\title{
Needs, Concerns and Constraints in Child-integrated Service Institution Projects
}

\author{
Eman Adil Jaafar \\ University of Baghdad
}

\begin{abstract}
The purpose of this study is to provide an overview of the various factors that influence children's multidimensional development. Childhood is widely regarded as the most essential phase of a person's life since it shapes the child's response to life's challenges. There are both evident and hidden social risks to a child's healthy growth. Family and society, which are frequently seen as safe havens for children, wilfully overlook this component. It is necessary to be aware of the psychosocial state of children who require care and protection. In certain ways, a person's ability to contribute to society as an adult is influenced by his or her formative experiences. Though, in general, this component is not given much attention in Indian society. Children are not given their due share in the country's development process, and little effort is made to bring them into the mainstream. This has a long-term effect on a child's physical, social, psychological, mental, and moral development. The paper begins by discussing children's developmental needs as well as the hurdles they face as a result of being abused and neglected, such as orphans, abandoned children, child beggars, and trafficked children.
\end{abstract}

Keywords: Child Protection, psycho-social impact, emotional needs, emotional hazards, positive childhood, Substance Abuse, Sexual exploitation

\section{Introduction}

The future of every country is greatly reliant on the quality of children it has at any given time. Children, who have the potential to become responsible citizens and a useful human resource, shape a country's destiny. The investment made in the education of this younger generation is a critical determinant of a country's development. Furthermore, we can assert that children are the future of community, nation, and humanity. Childhood years have a significant impact on a person's personality development and efficiency. In certain ways, a person's ability to contribute to society as an adult is influenced by his or her formative experiences. Though, in general, this component is not given much attention in Indian society. Children are not given their due share in the country's development process, and little effort is made to bring them into the mainstream. The majority of children in our culture are subjected to some type of abuse, which is a blatant violation of child protection laws. This has a longterm effect on a child's physical, social, psychological, mental, and moral development. A child who does not have a healthy childhood is exposed to several risky scenarios, which not only negatively affect the child's social functioning, but also have long-term psychosocial consequences. As a result, when children reach adulthood, they continue to struggle primarily in their personal lives and are unlikely to be able to contribute to society.

A human life is split into four stages: childhood, adolescence, adulthood, and old age. The first stage of life is critical because the experiences you have here might influence your behaviour, skill, and capability in the subsequent three stages. As a result, the significance of childhood should never be underestimated; rather, it needs top priority because it has a considerable impact on subsequent stages of life. Infancy/babyhood, early childhood, late childhood, pre-puberty, and adolescence are the different stages of childhood. The right to life extends to the unborn infant, so a child is born at the time of conception of the foetus. With the exception of a threat to the mother's life and apparent contraindications for medical or mental health disorders, national and international regulations have decreed that the foetus receives special protection during the gestation period.

\section{Who are Children in need of Care and Protection?}

Section 2 (14) of the Juvenile Justice (Care and Protection of Children) Act, 2015, provides a comprehensive list of children who can be declared as those in need of care and protection. The definition of a child in need of care and protection has been drafted in extensive detail and these include:

1) Who is found without any home or settled place of abode and without any ostensible means of subsistence; or

2) Who is found working in contravention of labour laws for the time being in force or is found begging, or living on the street; or

3) Who resides with a person (whether a guardian of the child or not) and such person-

a) has injured, exploited, abused or neglected the child or has violated any other law for the time being in force meant for the protection of child; or

b) has threatened to kill, injure, exploit or abuse the child and there is a reasonable likelihood of the threat being carried out; or

c) has killed, abused, neglected or exploited some other child or children and there is a reasonable likelihood of the child in question being killed, abused, exploited or neglected by that person; or

4) Who is mentally ill or mentally or physically challenged or suffering from terminal or incurable disease, having no one to support or look after or having parents or guardians unfit to take care, if found so by the Board or the Committee; or

5) who has a parent or guardian and such parent or guardian is found to be unfit or incapacitated, by the Committee or the Board, to care for and protect the safety and well-being of the child; or 
6) who does not have parents and no one is willing to take care of, or whose parents have abandoned or surrendered him; or

7) who is missing or run away child, or whose parents cannot be found after making reasonable inquiry in such manner as may be prescribed; or

8) who has been or is being or is likely to be abused, tortured or exploited for the purpose of sexual abuse or illegal acts; or

9) who is found vulnerable and is likely to be inducted into drug abuse or trafficking; or

10) who is being or is likely to be abused for unconscionable gains; or

11) who is victim of or affected by any armed conflict, civil unrest or natural calamity; or

12) who is at imminent risk of marriage before attaining the age of marriage and whose parents, family members, guardian and any other persons are likely to be responsible for solemnisation of such marriage;

Orphan children are a term used to describe children who have lost one or both parents. These youngsters lack the family atmosphere, as well as the social bonding and stability that the family provides. The primary role of a family in practically every society on the planet is procreation and child rearing. A child is made up of genetic endowments inherited from his or her parents, and he or she also learns the art of life while building social and emotional bonds with his or her parents and other important people in the surroundings. Parents are also expected to give the best possible care and nurture for their children, limited only by their financial resources and the state's social support. When one or both parents leave the home, there is a direct lack of social and emotional security, as well as financial uncertainty. A child's social support from his or her family allows him or her to acquire societal conventions and values, as well as to have a support system to lean on when life throws them a curve ball. Until a person is able to build his or her own family, a family plays a critical part in his or her life.

Abandoned children are individuals who are disowned by their biological parents for reasons that are more important to the parents than the child's best interests. In the same way that orphan children lack the love, affection, and emotional attachment of their parents, an abandoned kid goes through a period of great upheaval. This instils mistrust in others as a result of being rejected by one's own parents. Sometimes the child has no idea where he or she came from. This has left a lasting psychological scar. Although there are no clear-cut causes of child abandonment, general observation reveals that societal taboos associated with illegitimacy, a lack of financial support, the death of one of the parents, the child's gender, the parents' neglectful attitude, physical or mental abnormality, and other factors are major causes of child abandonment. When parents neglect their most important responsibility, childcare, the child faces enormous challenges in surviving. Adoptive parents, child behaviour problems, personality traits of institutionalised orphan girls, pre-school children living in slums, children of mentally ill parents, physically handicapped children, mental illness, adolescent girls, juvenile delinquents, runaway children, and other topics are covered in the various studies. It was discovered that adolescent institutionalised girls' psychological development is influenced by their mothers' affection. In terms of family relationships, it was discovered that the father did not play a significant role in the lives of girls, whereas the mother did. The lack of love from mothers had a negative impact on girls, who tended to be lonely and even neurotic as a result. It was discovered that orphan girls had lower social maturity and intellectual capacity (in terms of abstract and logical thinking) than non-orphan girls, although orphan girls had a higher neurotic tendency than non-orphan girls. Children from disadvantaged families have differing degrees of development, necessitating different types of treatments for different groups of children. Good parenting was discovered to be an essential aspect in achieving positive results.

Child beggary is also a form of organised crime that exists unchecked in our country. Children are used in child beggary because of their ability to elicit sympathy from the general public. Even in some homes, parents encourage children to beg on the streets, in religious buildings, in markets, and in residential neighbourhoods in order to provide for the entire family. Child begging is done in a variety of ways. According to the findings, parents or guardians may force youngsters to beg. Others, such as minors trafficked into begging by informal networks or organised criminal gangs, and forced child begging linked to drug addiction in India, are exploited in this way by third parties. (Delap, 2009). These children can easily be identified on the streets as being in a state of utter deprivation. They are also at risk of health problems as a result of air and noise pollution, as well as traffic accidents. They are also the target of the public's fury. The physical and mental development of child beggars is badly harmed, and this is due to a variety of factors other than a lack of schooling. They are constantly in danger of losing their lives, and they are also vulnerable to other dangers such as drug misuse, petty theft, and organised crime. Child beggars lack even the most basic of human needs, such as nutritious food, shelter, safe drinking water, cleanliness, correct clothing, health care, education, family bonding, safety, and value education.

Child trafficking entails the extreme exploitation of minors through other crimes such as child labour, beggary, child prostitution, child marriage, indoctrination into drug addiction, and militancy. Human trafficking entails the selling and purchase of human beings as commodities, with the person dealing in humans gaining a sort of property right over those who are bought. Despite the fact that the Immoral Traffic Prevention Act is in effect, vulnerable children's lives are oppressed to the fullest degree due to a lack of awareness about legal requirements and life's compulsions due to economic necessity. The state of deprivation prevents disadvantaged families from accessing basic necessities. And this provides ample justification for being seduced by high promises of a secure job, marriage, education, money, and so on. Our country's impoverished states provide us with cheap human lab animals on a regular basis. According to the National Human Rights Commission's (NHRC) Action Research Study (2005), the majority of trafficking victims are from socially disadvantaged groups, such as Scheduled Castes and Scheduled Tribes. Drought-prone locations and 
communities hit by natural or man-made calamities have a higher risk of falling prey to people trafficking. Young boys and girls are particularly vulnerable to exploitation for prostitution, laboratory work in the domestic, industrial, and entertainment sectors, drug addiction, and other illegal activities.

\section{What is Child Protection?}

Child protection is the prevention of or responding to the incidence of abuse, exploitation, violence and neglect of children. This includes commercial sexual exploitation, trafficking, child labour and harmful traditional practices, such as female genital mutilation/cutting and child marriage.

Integrated Child Protection Scheme (ICPS) further explains child protection as keeping children safe from a risk or perceived risk to their lives or childhood, recognizing that children are vulnerable and hence reducing their vulnerability by protecting them from harm and harmful situations.

Child in Need of Care and Protection (CNCP) means a child:
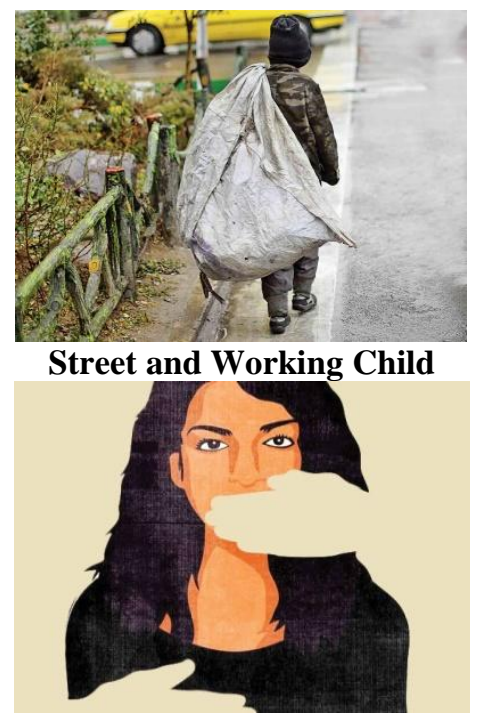

Children who are victims of Commercial Sexual

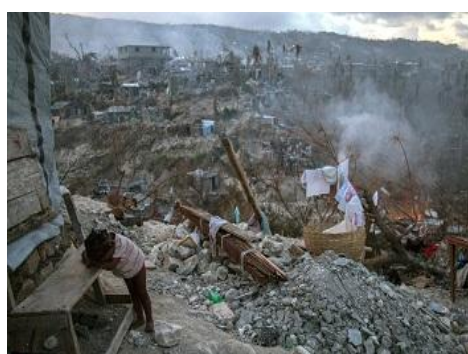

Children in armed conflict and disaster situations

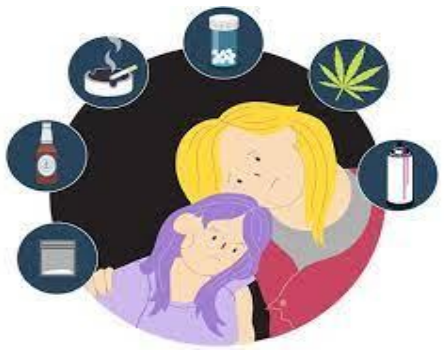

Children engaged in substance abuse
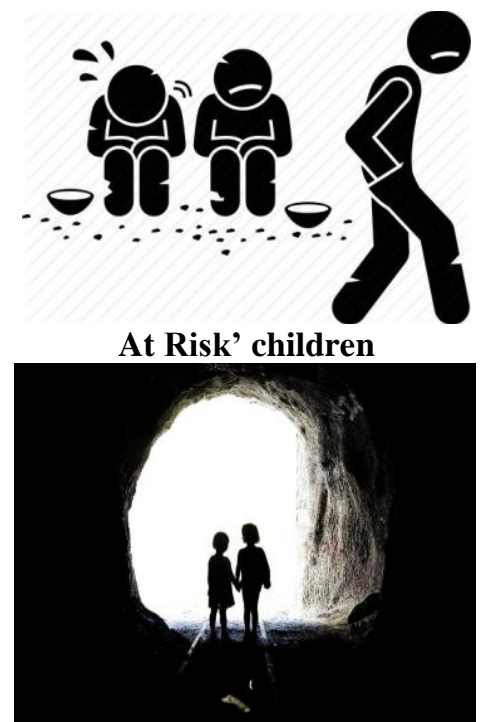

Orphan, abandoned and Exploitation and Trafficking

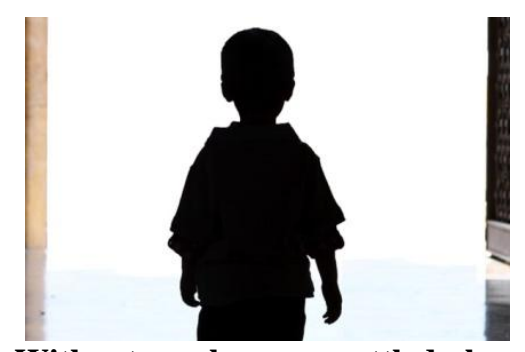

Without any home or settled place

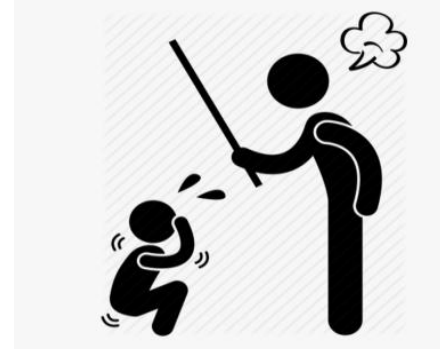

Abused children destitute

Facts and Figures about children

Census 2011 had counted more than 440 million children in India below 18 years of age constituting $37 \%$ of the total population of the country. Within the age group of 0-17 years, children between 0-6 years constituted about $14 \%$ of the total population of children in India followed by $17 \%$ between 7-14 years and the remaining $6 \%$ in the age group of $15-17$ years.

With an Infant Mortality Rate of 35 children dying before attaining one year of age per 1000 live births, the United Nation Population Division has ranked India as the 144th country out of a total of 188 listed countries as far as IMR is concerned.

According to NHRC Report, only $10 \%$ of human trafficking in India is international, while almost $90 \%$ is interstate.

\section{Children in difficult circumstances:}

- About 172 million or 40 per cent children.

- These children include:

- children without family support, 
- children forced into labour,

- abused/trafficked, children on streets,

- children affected by substance abuse,

- Children in armed conflict/civil unrest/natural calamity etc.

\section{Discussion}

The infancy phase is defined as the time between birth and one month of age. This stage is marked by the greatest reliance on the environment's primary caregivers for survival. The next stage is babyhood, which begins when the kid crosses the infancy stage and reaches the age of two. During this time, the infant begins to engage in activities that are unique to humans, such as walking, speaking, and socialising. At roughly three years of age, the kid enters preschool and starts its initial steps toward socialisation with teachers and peers, but remains mostly reliant on family for fundamental survival needs such as security. The child is then exposed to a formal education system and seeks out independent socialisation in late childhood. From one level to the next, all of these stages evolve in a progressive manner. The active realisation of goals in the subsequent stages is ensured by the achievement of milestones in the preceding stage. The following stage, pre-puberty, is marked by emotional upheaval and hormonal changes in the body, leading to identity crises and difficulty establishing a balance between self and societal expectations. As the youngster approaches reproductive age, changes in physical endowments begin to emerge. Adolescence marks the end of childhood and the start of adulthood.

The foundation that is built in childhood has a tremendous impact on a person's entire life span. Individuals' personalities are distorted as a result of a childhood lived in a state of acute deprivation. The 'hierarchy of needs, ' as described by Abraham Maslow, is a good example of this. A child who must struggle to meet his or her own fundamental physical and emotional requirements during the most vital years of growth and development is unlikely to reach the condition of self-actualization, and so lacks the ability to solve problems and respond to changing environmental demands. He argues that having appropriate resources for subsistence, such as food, shelter, clothing, health, and sleep, is critical; it is also critical to have a secure environment free of threats to life, health, and mental well-being. It also entails the availability of social security benefits derived from financial security, as well as social protection that extends beyond the towering barriers of class, creed, gender, or age differences. Maslow believes that an individual can only contribute productively to society once they have reached the stage of self-actualization. This stage occurs only when the individual's personal requirements, such as physiological, safety, emotional (love/belongingness), and esteem, are addressed. The family environment has a catalytic effect in the development of children. The family plays a crucial role in ensuring an individual's safety in the face of a variety of uncertainties and difficult life situations. However, when children are exposed to abuse in the family environment, which is otherwise considered to be the safest haven for an individual, the reality for some children is gruesome. Poverty, unemployment, family breakdown, migration, unhealthy lifestyles, crime against children, natural and manmade disasters, religious differences, social ostracization, armed conflict, exploitation of children's health and strength, denial of children's rights, and other factors can make the family environment hostile. The modern family is undergoing a profound societal transformation, and it is slipping away from its traditional duties of caretaker and protector; widespread urbanisation is one contributing factor. It may also result in family dysfunction, which is a state of disorganisation in the family's operating pattern. It refers to family members' failure to do basic, socially required responsibilities and functions that are necessary for the family's survival or the well-being of its members (Prasad, Khasgiwala, vaswani 2009 et al.).

According to the National Institute of Public Cooperation and Child Development (2009), family neglect can lead to child abuse, which is defined as "acts or omissions by a caregiver resulting in actual or potential damage to the child's health and development, and exposure to unnecessary suffering. " Child abuse is frequently perpetrated by individuals who are responsible for the care and safety of children. According to a research done by the Ministry of Women and Child Development (2007), parents were the emotional abusers in 83 percent of cases. Even though the children are raised in a typical family setting, they may need to be classified as children in need of care and protection. Even if they were raised in a family atmosphere, they sometimes lack the care and protection they need in adulthood. They may also be harmed as a result of parental negligence. This deprivation, which stems from neglect and abuse in the family, has a significant impact on the quality of nurture and the possibility to grow in a healthy setting. These children's mental health and ability to lead a healthy life are severely harmed by the neglect and apathy they are subjected to. Because direct cognizance of abusive parental acts is rarely taken, they continue to be the masked victims of abuse. The harsh reality is that youngsters in need of care and protection also lack the unconditional love and devotion of their loved ones. They are frequently ignored, exploited, emotionally harmed, and assaulted. This affects their selfesteem and ability to develop trust in others and form good relationships with important people in their lives, such as guardians, parents, carers, peers, and so on. They are frequently labelled as deviants and societal dangers since they are not empathetically understood. This inattentive attitude is the outcome of society's failure to realise the significance of meeting people's social and emotional needs. This could result in the infant developing incorrect personality features. A child who is not shown affection and love in his environment does not learn the importance of these feelings and does not value them later in life. Although this may appear to be a hypothetical construct for pure research, love and emotional connection have a proclivity for forming social bonds. Affectionate touch is a construct of development psychology because it acts as a stimulant for the development of the sensory system in children as well as increasing blood circulation in the body. The love and affection shown to children creates an invisible shield around them that protects them, allowing them to grow up to be emotionally and physically healthy adults. However, the absence of these emotions causes serious intangible suffering that affects their academic, health, and social 
development as well as their psychological well-being. Values instilled through observation of family members' behaviour and behaviour have a longer lasting impact than a million words of wisdom or scholastic knowledge.

Though it is first and primarily the obligation of natural parents or guardians to provide for the care of children, if they fail to do so or are incapable of doing so, the state assumes the role of the child's guardian. The government and civil society must perform the role of saviour for these youngsters, preventing them from succumbing to the whims of bad circumstances. These children are also referred to as "children in need of care and protection, " and the Juvenile Justice Act provides a more specific definition (2015).

\section{Conclusion}

All of the groups of children described in this paper are those that are considered to be youngsters in need of care and protection. They are either exposed to traumatic events as a result of physical, sexual, emotional, or mental abuse or neglect as a result of their status. Physical abuse against children includes kicking, battering, shaking, or arduous work, and it can cause the victim to acquire the 'batteredchild syndrome, ' hindering the child's growth and mental and emotional development. Emotional and sexual abuse, on the other hand, has a negative impact on their physical growth as well as their social, emotional, and cerebral development. The vulnerable child is not given sufficient attention in India, where mental and emotional health is given the least emphasis. An abusive scenario might cause a child's conduct to become erratic, jeopardising her or his ability to adapt to society. The importance of early childhood care in the development of not only the kid but also society as a whole cannot be overstated. Even children in families are vulnerable to abuse, but the terrible aspect is that it frequently goes unrecognised and unregulated. Kid neglect is another form of abuse in which the person in charge of the child's upbringing and care fails to do it correctly, putting the child in danger by exposing him to potentially dangerous situations that could have been avoided.

The discussion also leads us to consider the severe emotional turmoil that the children have to face at three levels-when the child is actually going through difficult circumstances, during the pendency of proceedings against child abuse and lastly but not the least, the long term psychological impact of the whole process which s/he goes through. In situations where the abuse is meted out by a trustworthy person, the trauma is even more severe. In fact, the fear of being ridiculed, penalized and social pressure prevents them from seeking any remedial action. It is the need of the hour to arouse ourselves about the impact of the psychological harm that accrues to the children in need of care and protection, even if they are rescued from the difficult circumstances. Even the tiniest exposure to bad experiences in life leaves a lasting mark on the minds of children. As a result, there is a pressing need to educate parents and the general public on the value of a happy childhood. The primary goal should be to prevent or minimise the likelihood of exploitation or harm to children of any kind. It is necessary to convey to parents and caregivers the link between a shattered childhood and reduced social functioning later in life. The programming that an individual experiences as a youngster shapes an adult's personality. There are some circumstances that are beyond an individual's control, but in the vast majority of cases, a kid is the victim of parental and family neglect. The quality of childhood is also influenced by strained parentchild relationships. It is not required for a child to be vulnerable to a tough scenario only as a result of the direct impact of situations on his or her own life, but also as a result of the impact that percolates to her or him as a result of breakdowns in the lives of family members. These factors play a critical part in determining a child's psychological strength throughout his life. A child who is denied this opportunity in his early years would most likely show signs of maladjustment later in life. As a result, a person's personality framework is shaped by his or her childhood experiences. The ability to frame inferences of the circumstance and demonstrate a positive or negative response while addressing the scenario is determined by a person's personality.

According to Sengupta (2001), children who see violence against their moms in the household are affected in a variety of ways. They are frequently ignored and labelled as "victims of domestic violence. " In Indian society, there are few supports accessible for women who are subjected to domestic violence because patriarchy considers such violence as normal. This study examined the consequences of violence on children and adolescents who watched their dads abusing their mothers, as well as the distinctions, if any, between the impacts on boys and girls, taking into account the fact that a girl is raised to believe that marriage is the sole objective in life. Data was gathered from experts in a variety of areas whose clients had been victims of domestic violence, as well as their children. For the study, 250 mothers from Kolkata were chosen. The majority of adults in India still favour the use of violence against children as a form of imparting discipline, according to the findings. Around $21 \%$ of adolescents report experiencing physical or emotional abuse at home, and $26 \%$ report witnessing their mothers' abuse. Another noteworthy finding of this study is the impact of ongoing violence on women's relationships with their children. Many mothers do everything they can to keep their children safe from abuse and the awareness of the violence they are witnessing. The silence of the mother makes it more difficult for the child to express his or her feelings and experiences. A number of mothers stated that their children were the source of all their joys and expectations in life. It is natural for them to mistreat their children if they do not meet the enormous standards that these ladies have set for them. It is an established truth that all stages of a child's development are interdependent because the experiences of the previous stage have an impact on the successful completion of developmental tasks in the subsequent stage. Failure to complete development duties results in a variety of risks, many of which indicate a failure in social adjustment to expected responsibilities. The person's inability to lead a meaningful and purposeful life is the result of the incorrect development. And we immediately become judge mental, condemning the individual for their wrongdoings, oblivious to the fact that the person's personality qualities are not completely his/her 
responsibility. The environment has a significant impact on a person's personality development. This also influences how a person reacts to life situations in the future. We often overlook the fact that physical, social, economic, and environmental elements all have an impact on an individual's life. It is not simply the loss of a single person, but of humanity as a whole, because a civilization is made up of smaller components, or individuals. The strength of a community is determined by the quality of its members, and if the child population is neglected, the society is likely to be made up of people who lack good personality attributes. Only by being aware of the psychological needs and elements that influence the mental health of the kid population can our efforts to provide child protective norms and a child-friendly system serve the children in need of protection. The most important goal should be to return any youngster who has come into touch with the police to a normal context with minimal or no psychological harm. Currently, the focus is on physical repair, but the amount of psychological injury that the child will bear for the rest of his or her life must be minimised, if not eliminated, throughout the process. The sad reality is that in our culture, this perfect circumstance is a misnomer, and children continue to face challenges to their innocence in a variety of ways that cannot be counted in exact numbers.

\section{Recommendations to address}

To address the psychological harm that children in need of care and protection face, considerable actions must be taken at the grassroots level to provide benefits to each and every CNCP child in order to improve their future prospects.

Establishment of child-friendly centres, at least at the subdistrict level, with permanent psychologists and experts on staff Liaising with insurance companies for children's health insurance plans that are tailored to their needs.

Adults should be made aware of children in difficult situations through awareness programmes at school and university level. They could be given workshops and training programmes for ICPS Scheme.

Encourage collaboration with other national and international organisations who are interested in developing new ideas that will help children attain long-term development. Facilitate social and economic efforts that will enable children to attain long-term sustainable development.

\section{References}

[1] Prasad, B. D., Khasgiwala A., Vaswani. T. Resource Document, Families in Difficult Situations.2009, Availablefrom: URL: http: //www.css. ac. in/download/deviprasad/Article\%20N o.4. pdf

[2] National Institute of Public Cooperation and Child Development, New Delhi Child abuse: An overview. Bureau of Police Research and Development, Research Abstracts on Children in Need of Care and Protection, 2009

[3] Ministry of Women and Child Development, India, A study on child abuse in India 2007
[4] Official Gazette. The Juvenile Justice (Care and Protection of Children) Act, 2015.

[5] Esch, T., Stefano, G. B. . The Neurobiology of Love, Neuroendocrinology Letters No.3 June 2005; 26. Availablefrom: URL: http: //66.199.228.237/boundary/addiction/boundary/

[6] Neurobiology of love loveaddiction. pdf

[7] Jawahar Devi Birla Institute of Home Science, Calcutta (1999). Children in difficult circumstances: Abstracts of Research Studies.

[8] Census of India data-Data from 3rd National Family Health Survey (NFHS-5)

[9] Research reports published by the UN agencies

[10] Research reports of various government \& nongovernment organizations

[11] Delap, E. . Begging for Change: Research findings and recommendations on forced child begging in Albania/Greece, India and Senegal. Anti-Slavery International 2009, Available from: URL: http: //www.antislavery.

org/includes/documents/cm_docs/2009/b/beggingforch ang e09. pdf.

[12] National Human Rights Commission, Action Research Study (2005). Report on the Trafficking of Women \& Children in India 2002-2003.

[13] Prayas, New Delhi Children on the wheels: Issues of child protection and the situational assessment exercise of the railway children in New Delhi Railway Station. A PrayasSathi Joint Report, 2007

[14] Sengupta, S. Effects on children who witnessed abuse of their mothers. School of Women's Studies, Jadavpur University, Kolkata.2001.

[15] Dr. Nancy Mengi-Children in Need of Care and Protection in India: Needs, Concerns and Predicaments, International Journal of Scientific Research and Reviews 